DOI: $10.17805 /$ zpu.2019.4.6

\title{
«Третья миссия»в программах развития российских университетов (на примере вузов Северо-Западного федерального округа)
}

\author{
Е. В. КУДРЯШОВА, С. Э. СОРОКИН \\ СЕВЕРНЫЙ (АРКТИЧЕСКИЙ) ФЕДЕРАЛЬНЫЙ УНИВЕРСИТЕТ \\ ИМЕНИ М. В. ЛОМОНОСОВА
}

В статье анализируются программы развития ряда университетов Северо-Западного федерального округа России в части реализации ими задач «третьей миссии» - выполнения социальных функций. Выделены особенности реализации «третьей миссии», в зависимости от статуса университета, его миссии, целей и задач, основные направления взаимодействия образовательных организаций высшего образования с органами региональной власти, сферой производства и местным сообществом.

В качестве значимого для себя элемента большинство университетов видят коммерциализацию научных знаний и трансфер технологий с акцентом на инновационно-предпринимательской составляющей реализации «третьей миссии». Приоритетными также являются установление взаимовыгодных партнерских отношений с производством, государственными учреждениями и органами власти, трансфер технологий, консультирование и экспертиза. Участие в социально-культурной жизни региона или макрорегиона, как правило, рассматривается во вторую очередь.

Авторы приходят к выводу, что успешность реализации университетами «третьей миссии» будет во многом зависеть от позиции федеральных органов управления системой высшего образования, которые должны четко обозначить значимость этого направления. Ключевые слова: университет; национальный университет; федеральный университет; национальный исследовательский университет; опорный университет; “третья миссия»; высшее образование России; Северо-Западный федеральный округ

\section{ВВЕАЕНИЕ}

$\Pi$ роцессы трансформации российской системы образования ставят перед университетами новые задачи, предполагающие расширение спектра направлений деятельности, повышение их роли в жизни общества. Решение этих задач непосредственно связано с реализацией университетами «третьей миссии», которая наряду с образовательной и научной представляет собой необходимый элемент жизнедеятельности современной образовательной организации высшего образования.

В зарубежной образовательной практике дискуссии о «третьей мисси» университетов начали проявляться еще в 1960 -х гг. Вместе с тем в российской системе образования и научном сообществе о «третьей миссии» университетов серьезно заговорили в середине 2000-х гг. Именно в это время начинают появляться первые исследования по данной проблематике таких ученых, как А. А. Аузан (Аузан, 2013), Н. В. Головко, О. В. Зиневич, Е. А. Рузанкина (Головко, Зиневич, Рузанкина, 2018), В. И. Аобреньков, В. Я. Нечаев (Аобреньков, Нечаев, 2003), Н. А. Медушевский (Медушевский, 2016), О. В. Перфильева (Перфильева, 2011), В. А. Смирнов, А. А. Фадеева, Е. А. Пунина С. В. Голубев (Смирнов, Фадеева, Пунина, Голубев, 2013), В. А. Нагорнов (Нагорнов, Перфильева, 2010) и др. В них «третья миссия» анализируется с различных позиций: взаимодействие университета и региона, социальная ответственность университетов, стейкхолдерский подход к деятельности университетов.

В 2017 г. появился Московский международный рейтинг «Три миссии университета», в котором под «третьей миссией» подразумевается взаимосвязь университета 
и местных сообществ, приобретающая все большее значение как фактор гармоничного развития регионов 1 .

Отметим, что в научной литературе используются, как правило, три термина «третья миссия» (third mission), «третья роль» (third role) и «третье направление» (third stream). Обычно, во всех случаях речь идет о тождественных понятиях.

Целью статьи является анализ программных документов российских образовательных организаций высшего образования с точки зрения представленности в них элементов «третьей миссии». В качестве источниковой базы исследования выступили как теоретические работы зарубежных и российских авторов, посвященные проблемам реализации «третьей миссии» университетов, так и практический материал нормативные правовые акты органов управления образованием Российской Федерации, программы развития университетов.

Анализ различных форм реализации «третьей миссии», которые свойственны университетам с разным статусом, позволит сделать выводы об общих чертах и особенностях этого процесса, которые обусловливаются миссиями и стратегическими целями образовательных организаций.

В качестве объекта исследования нами были выбраны университеты, находящиеся на территории Северо-Западного федерального округа и обладающие различным статусом - национальный (Санкт-Петербургский государственный университет), федеральный (Северный (Арктический) федеральный университет имени М. В. Аомоносова (САФУ)), национальный исследовательский (Санкт-Петербургский государственный университет информационных технологий, механики и оптики (ИТМО)) и опорный (Псковский государственный университет (ПсковГУ)). Исследование производится на основе анализа программ развития этих университетов в части, касающейся реализации ими «третьей миссии». Безусловно, деятельность университетов выходит за рамки реализации программ развития, вместе с тем отражение вопросов, относящихся к «третьей миссии», в стратегических документах говорит о наличии или отсутствии приоритета данного направления в работе университета.

\section{ОПРЕАЕАЕНИЕ ПОНЯТИЯ}

В российской научной литературе встречаются следующие подходы к пониманию «третьей миссии» университетов: «особенный фокус деятельности университетов, связанный с ориентацией вуза на потребности общества в целом и отдельных граждан в частности, а также активная социальная позиция университета в отношении своей территории, обусловленная многосторонним взаимодействием с различными заинтересованными участниками», «включенность университета в решение значимых для общества проблем» (Головко, Зиневич, Рузанкина, 2018: 7).

Н. А. Медушевский и О. В. Перфильева в качестве содержательных компонентов «третьей миссии» университетов выделяют передачу технологий (создание технопарков, интеграция в производственные кластеры, $R \& \mathrm{D}^{2}$ ), социальные обязательства (взаимодействие с обществом, регионом, НКО, направленное на содействие социальному развитию) и обучение в течение всей жизни (переподготовка кадров, повышение квалификации, тренинги) (Медушевский, 2016: 21).

К характеристикам «третьей миссии» университета ряд исследователей относит также «генерирование, практическое применение знаний, получение выгоды от ресурсов (помещения, техника) за пределами академической среды» (Jongbloed, 2008: 87); 
«экономическое применение исследований, патентов, трансфер технологий, а в широком смысле - любую деятельность в направлении общества» (Dan, 2012: 52).

О. В. Перфильева называет «социальным участием» университета «понимание и учет общественных потребностей в обучении граждан, подготовке специалистов для конкретных отраслей производства, проведении конкретных научных исследований Аля решения проблем, актуальных для сообщества, на основе многостороннего взаимодействия с различными заинтересованными участниками» (Перфильева, 2011: 135).

О трех движущих факторах, которые определяют «третью миссию», - социальном, предпринимательском и инновационном пишут П. Монтенсинос, Аж. М. Карот, Аж. Мартинез и Ф. Мора (Montesinos, Carot, Mora, 2008: 197). Социальный фактор это сфера, в которой не предполагается извлечение прибыли или экономический эффект. Это область оказания социальных услуг, участия университета в развитии городских пространств, взаимодействия с местным сообществом, культурной среды, студенческой активности. Предпринимательский фактор связан с проведением научных исследований по контрактам с государством и бизнесом, коммерциализацией интеллектуальной собственности, платными образовательными программами, использованием объектов университета на коммерческой основе. Инновационный фактор предполагает внедрение научных разработок университетов, консультирование органов власти и правительственных организаций.

При рассмотрении проблематики «третьей миссии» университетов большинство как зарубежных, так и российских авторов обращаются к работе «Методология третьей миссии университетов» М. Мархла и А. Паусиста, в которой дается определение «третьей миссии»: «совокупность специфических услуг, основанных на действиях и возможностях, служащих для блага общества» (Мархл, Паусист: 2013).

Авторы анализируют систему элементов, относящихся к третьей миссии, и выделяют восемь ее критериев: человеческие ресурсы, интеллектуальная собственность, коммерциализация результатов индивидуальных и групповых научных исследований, контракты с производством, контракты с государственными учреждениями, участие в процессе принятия решений, вовлеченность в социально-культурную жизнь, результаты трансфера знаний в общество.

\section{«ТРЕТЬЯ МИССИЯ» В ПРОГРАММЕ РАЗВИТИЯ СПБГУ}

Программа развития Санкт-Петербургского государственного университета до 2020 года была утверждена распоряжением Правительства РФ от 7 октября 2010 г. Приоритетными направлениями программы названы нанотехнологии и материаловедение; биомедицина и здоровье человека; информационные системы и технологии; экология и рациональное природопользование; социальные исследования и технологии; управленческие кадры и технологии ${ }^{3}$. Последние два направления можно в полной мере отнести к реализации «третьей миссии», хотя и по ряду других также возникают социальные эффекты, направленные на решение задач устойчивого развития страны.

Если рассматривать программу через призму системы распознавания элементов, относящихся к «третьей миссии», можно выделить следующее:

1) зафиксированы вопросы развития интеллектуальной собственности и коммерциализацией научных исследований. Так, в числе индикаторов программы представлены такие, как количество объектов интеллектуальной собственности, правообладателем которых является университет; количество поданных заявок на защиту объек- 
тов интеллектуальной собственности, доля доходов от реализации объектов интеллектуальной собственности в общем объеме средств от приносящей доход деятельности, количество хозяйственных обществ, обеспечивающих практическое применение результатов интеллектуальной деятельности;

2) акцент на развитие контрактов с государственными учреждениями. Стратегическая цель университета - становление его как центра, исполняющего государственные заказы в области инновационного развития, аналитики, научного, экспертного и правового обеспечения структурной диверсификации экономики и обеспечивающего устойчивое функционирование государственных и общественных институтов;

3) отражены вопросы, связанные с позицией «участие в процессе принятия решений». Университет планирует мероприятия, связанные с развитием университетского экспертного сообщества, расширением экспертной и консалтинговой деятельности;

4) в программе не отражены позиции, связанные с участием университета в социально-культурной жизни города, трансфером знаний в общество, контрактами с производством и вопросами передачи сформированных в процессе научно-исследовательской деятельности компетенций в сферу производства и оказания общественных услуг.

В целом можно сделать вывод о том, что результаты реализации программы имеют общероссийскую направленность, т. е. не привязаны ни к региону нахождения университета, ни даже к федеральному округу. Статус национального университета предполагает ориентацию на решение общефедеральных задач.

Университет прямо обозначает себя как центр подготовки российской управленческой әлиты, обеспечивающей устойчивое развитие государственных и общественных институтов, таким образом, принимая на себя социальную ответственность за формирование будущего российского государства в целом.

\section{«ТРЕТЬЯ МИССИЯ» В ПРОГРАММЕ РАЗВИТИЯ САФУ}

Программа Северного (Арктического) федерального университета имени М. В. Аомоносова была утверждена распоряжением Правительства РФ 19 августа 2009 г.

Миссия университета - создание инновационной научной и кадровой базы для интеллектуального освоения Севера России и Арктики. В качестве стратегической цели университета обозначено научное и кадровое обеспечение защиты геополитических интересов России в Арктике, формирование интеллектуального центра, способствующего развитию арктических территорий РФ 4 . Еще одна стратегическая задача, идущая в контексте «третьей миссии» университета, - воспитание патриотической молодежи, готовой к развитию арктических территорий. Таким образом, сферой своей социальной ответственности университет видит не только регион своего местонахождения, но и более обширную территорию Арктической зоны РФ.

Рассматривая программу в контексте системы распознавания элементов, относящихся к «третьей миссии», можно сделать следующие выводы:

1) в программе так или иначе отражено большинство позиций, за исключением блоков «контракты с государственными учреждениями» и «результаты трансфера знаний в общество», хотя известно, что данная работа университетом проводится;

2) среди индикаторов программы важное место занимают вопросы интеллектуальной собственности и коммерциализации результатов индивидуальных и групповых научных исследований: количество поставленных на учет объектов интеллектуальной собственности, доля доходов от реализации объектов интеллектуальной соб- 
ственности в общем объеме средств от приносящей доход деятельности, объем научно-исследовательских и опытно-конструкторских работ, количество проектов с участием студентов, аспирантов и выпускников университета, реализованных в инновационных структурах (бизнес-инкубаторы, технопарки, центры трансфера технологий и др.);

3) программа предполагает активное участие университета в общественной и социально-культурной жизни как региона своего местонахождения, так и Арктической зоны. В программе развития обозначено «становление университета как опорного элемента социальной и культурной инфраструктур Европейского Севера России и Арктики»;

4) в качестве зоны своего политического влияния университет видит не только территорию субъекта Федерации, но и весь Арктический регион. В качестве одного из результатов программы видится становление университета как «территории диалога в сфере образования, научных исследований и инноваций Арктического региона и всего мира».

Таким образом, статус федерального университета определяет, во-первых, вектор приложения усилий университета (Арктический регион) и как следствие - зону его интересов, в том числе и в контексте «третьей миссии», а во-вторых, создает предпосылки для активного взаимодействия с местным сообществом не только в образовательной, но и в социальной жизни.

\section{«ТРЕТЬЯ МИССИЯ» В ПРОГРАММЕ РАЗВИТИЯ ИТМО}

Программа развития Санкт-Петербургского государственного университета информационных технологий, механики и оптики на 2009-2018 годы была утверждена распоряжением Правительства РФ от 17 ноября 2009 г. ИТМО имеет статус национального исследовательского университета.

Несмотря на то что развитие университета имеет достаточно сфокусированную направленность на усиление конкурентных преимуществ России в сфере информационных и оптических технологий в условиях мировой глобализации, можно выделить ряд элементов реализации «третьей миссии» в программе его развития. Прежде всего, обращает на себя внимание ориентация на коммерциализацию научных исследований как один из приоритетов в работе, а также на развитие инновационной деятельности.

Так, среди мероприятий программы предполагается совершенствование инновационной структуры университета, повышение квалификации его сотрудников в части организации процесса трансфера технологий и коммерциализации научных разработок, создание бизнес-инкубатора для сотрудников, формирование системы организационной, технологической и экономической экспертизы коммерческих проектов 5 .

В качестве партнеров университет видит компании высокотехнологичных отраслей промышленности.

На наш взгляд, в программе развития ИТМО присутствуют черты так называемого предпринимательского университета. Впервые этот термин был введен американским ученым Б. Кларком, который в работе «Создание предпринимательского университета: организационные пути трансформации» (Кларк, 2011: 59) провел эмпирическое исследование трансформации пяти европейских университетов в течение десяти лет. При этом в ходе исследования употреблял как термин «предпринимательский», так и термин «инновационный» университет, считая их практически синонима- 
ми, однако в результате остановился на первом, как наиболее точно отражающем суть преобразований.

Развитие идеи предпринимательского университета мы видим в работах профессора Стэнфордского университета Г. Ицковица и профессора Амстердамского университета $\Lambda$. Аейдесдорфа, которые выдвинули концепцию «Тройной спирали». В нее входят государство, университет и бизнес, причем ключевую роль играют именно университеты, обладающие потенциалом по производству новых знаний и научных исследований (Ицковиц, 2010). Аля организации процесса при университетах создаются структуры, необходимые для предпринимательской деятельности, - технопарки, бизнес-инкубаторы, дочерние фирмы.

Авторы пишут о том, что у университетов появляется новая, предпринимательская функция вследствие «второй академической революции». Под этим явлением они подразумевают коммерциализацию научного знания, превращение информации в интеллектуальную собственность, а научной политики - в часть экономической политики на уровне государства (там же: 118).

В рамках «предпринимательской миссии» университеты, опираясь на существующий научный потенциал, развивают фундаментальные и прикладные исследования, выстраивают систему инновационной науки, образования и подготовки специалистов, включающую в себя «полный цикл» от создания научного или образовательного продукта до его внедрения. Безусловно, для этого необходимы устойчивые партнерские связи между университетом, бизнесом, производством и государством, а также наличие системы стимулирования к инновационной деятельности, принятию принципов культуры предпринимательства.

Все это мы видим в программе развития ИТМО, который обладает значительным инновационным потенциалом.

В качестве одного из результатов программы предполагается внедрение механизма государственно-частного партнерства для развития преимуществ в области информационных и оптических технологий.

Также вызывает интерес блок задач, связанных с внедрением внешних механизмов общественно-профессионального оценивания качества образования для контроля компетенций выпускников и оценивания бизнесом практико-ориентированных образовательных программ.

Как и в случае с национальным университетом - СПбГУ, ИТМО также ориентирован на решение задач общефедерального уровня, и в программе его развития нет привязки к региону или федеральному округу, а социальные и экономические эффекты от его деятельности могут затрагивать широкие слои населения, государственные, деловые и общественные структуры.

\section{«ТРЕТЬЯ МИССИЯ» В ПРОГРАММЕ РАЗВИТИЯ ПСКОВГУ}

Программа развития Псковского государственного университета, получившего статус опорного, утверждена ректором университета и согласована губернатором Псковской области 16 октября 2017 г.

Опорные вузы создаются с целью «поддержки развития субъекта Российской Федерации посредством обеспечения местного рынка труда высококвалифицированными специалистами, решения актуальных задач региональной экономики и реализации совместно с регионом и его предприятиями образовательных и инновационных проектов» ${ }^{6}$. Следовательно, реализация опорным университетом «третьей миссии», на- 
правленной на активное участие в развитии региона, априори должна получить свое отражение в программе развития.

Это можно увидеть на примере Псковского государственного университета, программа развития которого содержит практически все элементы «третьей миссии».

Миссия университета - проведение научно-исследовательских и инновационнотехнологических работ в интересах социально-экономического развития Псковской области и подготовка на их базе высококвалифицированных, конкурентоспособных, ориентированных на профессиональную карьеру специалистов ${ }^{7}$.

Среди показателей эффективности программы мы видим долю выпускников, трудоустроившихся в регионе нахождения университета, совершенствование научно-инновационной инфраструктуры, интенсификацию процесса создания и коммерциализации охраноспособных результатов научно-технической деятельности, совокупный доход малых инновационных предприятий, созданных при университете, количество команд-резидентов бизнес-инкубаторов и технопарков университета.

В качестве приоритетного направления работы университет обозначает работу по подготовке кадров для социально-экономического развития региона. Среди мероприятий программы модернизация и расширение подготовки кадров для реального сектора экономики Псковской области, развитие и совершенствование педагогического образования в регионе для малокомплектных школ, внедрение проектно-ориентированных программ подготовки кадров и совершенствования механизмов взаимодействия с работодателем и ряд других.

Совместно с региональной властью планируется создание Центра инноваций электротехнического кластера Псковской области и особой экономической зоны промышленного производства «Моглино».

Значительная часть программы посвящена вопросам участия университета в социально-культурном развитии региона. В качестве прорывных предлагается ряд проектов, направленных на решение социальных проблем Псковской области.

Отдельный блок мероприятий программы посвящен участию университета в развитии местных сообществ, городской и региональной среды с акцентом на вовлечение в эти процессы студентов.

В дорожной карте программы предусмотрена реализация общественно-политических, информационных проектов для региона, что можно рассматривать как элемент трансфера знаний в общество.

Университет видит себя участником процесса выработки и принятия политических решений в регионе. Аля этого по программе планируется создание центра экспертизы и консультирования субъектов общественно-политических отношений.

Таким образом, опорный Псковский государственный университет ставит себе задачу стать важным элементом социально-экономического развития региона, принимая на себя социальную ответственность за его будущее.

\section{ЗАКАЮЧЕНИЕ}

Проведя анализ особенностей программ развития четырех университетов СевероЗападного федерального округа, имеющих различные статусы, в контексте реализации ими «третьей миссии», можно сделать выводы.

1. Во всех рассмотренных программах развития отсутствует прямое упоминание понятия «третья миссия». Это объяснимо в том числе и тем, что эти программы создавались в начале 2010-х гг., когда о «третьей миссии» на уровне руководства сферой 
образования страны еще не говорили. Возможно, мы увидим этот аспект в новых программах развития, большинство из которых заканчивает свое действие в 2020 г.

2. Статус университета является определяющим при выборе университетами приоритетных направлений, форм и механизмов реализации «третьей миссии».

Это обусловливается, во-первых, задачами, исходящими из его статуса, а во-вторых, пространством, на которое распространяются результаты его деятельности. Так, федерально ориентированные университеты либо совсем не рассматривают регион своего местонахождения как точку приложения усилий (национальный и национальный исследовательский), либо рассматривают его в связке с более крупным макрорегионом (федеральный). Регионально ориентированные университеты, имеющие статус опорного, наоборот, в своих устремлениях не выходят за границы соответствующего субъекта Федерации.

Однако, к примеру, для Северного (Арктического) федерального университета, который является крупнейшим из двух государственных образовательных организаций, работающих на территории Архангельской области, возникла ситуация, когда он принял на себя большой блок задач, связанных с обеспечением кадрами экономики региона, взаимодействием с региональным производством и бизнесом, активным участием в его социально-культурной жизни, тем самым «раздваивая» фокус своего внимания - на Арктический регион в целом и на Архангельскую область в частности.

3. Большинство университетов в качестве значимого для себя элемента видят коммерциализацию научных знаний и трансфер технологий, тем самым делая акцент на инновационно-предпринимательской составляющей реализации «третьей миссии». Приоритетными являются установление взаимовыгодных партнерских отношений с производством, государственными учреждениями и органами власти, трансфер технологий, консультирование и экспертиза. Участие в социально-культурной жизни региона или макрорегиона, как правило, рассматривается во вторую очередь.

4. Участие университета в развитии субъекта Федерации - места его нахождения наиболее четко отражено в программе развития опорного университета (ПсковГУ) и федерального (САФУ). Федерально ориентированные университеты - национальный (СПбГУ) и национальный исследовательский (ИТМО) практически не обозначают свою связь с регионом, в котором они находятся.

5. Можно отметить наличие потенциала для повышения значимости «третьей миссии» в программах развития университетов, которые будут приниматься в будущие периоды. Этому будет способствовать в том числе и позиция федеральных органов управления системой высшего образования, которым, на наш взгляд, необходимо более четко обозначать значимость этого направления в жизнедеятельности образовательных организаций.

В этом случае развитие российских университетов будет соответствовать современным тенденциям, что повысит их конкурентоспособность в мировом образовательном пространстве, а также даст дополнительные ресурсы для развития внутри страны.

\section{ПРИМЕЧАНИЯ}

${ }^{1}$ Московский международный рейтинг «Три миссии университета» URL: https:// mosiur.org/files/methodology_17/RU-MOSIUR_Methodology_28072017.pdf (дата обращения: 02.10.2019).

2 R\&D (Research and Development) - научно-исследовательские и опытно-конструкторские разработки. 
3 Программа развития федерального государственного бюджетного образовательного учреждения высшего профессионального образования «Санкт-Петербургский государственный университет» до 2020 года / Санкт-Петербургский государственный университет. URL: https://spbu.ru/sites/default/files/programm.2.pdf (дата обращения: 04.06.2019).

4 Программа развития федерального государственного автономного образовательного учреждения высшего профессионального образования «Северный (Арктический) федеральный университет имени М. В. Аомоносова» на 2010-2020 годы / Северный (Арктический) федеральный университет имени М. В. Аомоносова. URL: https://narfu.ru/upload/medialibrary/df9/ 1604_r_programma-razvitiya-safu.pdf (дата обращения: 04.06.2019).

5 Программа развития национального исследовательского университета (Программа развития НИУ ИТМО) / Университет ИТМО. URL: http://www.ifmo.ru/ru/page/174/programma razvitiya_nacionalnogo_issledovatelskogo_universiteta_programma_razvitiya_niu_itmo.htm\#ixzz5 qSVs8I62 (дата обращения: 04.06.2019).

6 Эксперты: опорные вузы получат новые возможности для развития (2016) // РИА-Новости. 17 мая. URL: https://na.ria.ru/20160517/1434231787.html (дата обращения: 04.06.2019).

7 Программа развития федерального государственного бюджетного образовательного учреждения высшего образования «Псковский государственный университет» на 2017-2021 годы / Псковский государственный университет. URL: https:/pskgu.ru/download.php/pskgu/files/PAGES/IMAGES/ 96174c89-c966-4429-80ba-05232e33e90f/AADF03FF3F3DED86C225400E992B5B0F (дата обращения: 04.06.2019).

\section{СПИСОК АИТЕРАТУРЫ}

Аузан, А. А. (2013) Миссия университета: взгляд экономиста // Вопросы образования. № 3. C. $266-286$.

Головко, Н. В., Зиневич, О. В., Рузанкина Е. А. (2018) Третья миссия университета и модель многопользовательского управления для регионального развития // Сравнительная политика. № 1. C. 5-17.

Аобреньков, В. И., Нечаев, В. Я. (2003) Общество и образование. М. : ИНФРА-М. 381 с.

Зиневич, О. В., Рузанкина Е. А. (2014) Университет как научный и социальный институт в современном российском обществе // Высшее образование в России. № 7. С. 37-43.

Ицковиц, Г. (2010) Тройная спираль. Университеты - предприятия - государство. Инновации в действии : пер. с англ. под ред. А. Ф. Уварова. Томск : Изд-во Томск, гос. ун-та систем упр. и радиоэлектроники. 238 с.

Кларк, Б. Р. (2011) Создание предпринимательских университетов: организационные направления трансформации / пер. с англ. А. Смирнова. М. : Изд. дом Гос. ун-та - Высшей школы экономики. 240 с.

Мархл М., Паусист А. (2013) Методология оценки третьей миссии университетов // Непрерывное образование: XXI век. Вып. 1. С. 1-13.

Медушевский, Н. А. (2016) Интерпретация третьей роли университетов на современном этапе // Вестник РГГУ. Серия «Политология. История. Международные отношения. Зарубежное регионоведение. Востоковедение». № 3. С. 19-31.

Нагорнов, В. А., Перфильева, О. В. (2010) Оценка роли вузов в региональном развитии: формирование устойчивых партнерств для взаимодействия // Вестник международных организаций: образование, наука, новая экономика. № 4. С. 60-86.

Перфильева, О.В.(2011) Университет и регион: на пути к реализации третьей функции // Вестник международных организаций. № 1 (32). С. 133-144.

Смирнов В. А., Фадеева А. А., Пунина К. А., Голубев С. В. (2013) Университет и региональные (городские) сообщества: модели сосуществования и управленческие механизмы интеграции (российский и европейский опыт) // Ars Administrandi. № 4. C. 102-117.

Dan, M. C. (2012) The Third Mission of Universities in the Development Strategy of Vienna City // Informatica. Economica. Vol. 16. № 4. P. 49-56. 
Jongbloed, B. (2008) Seven Indicators for Mapping University regional Interactions // ENID PRIME Indicators Conference in Oslo, 26-28 May 2008. London : Publisher Centre for Higher Education. 123 p.

Montesinos, P., Carot, J.-M., Mora, F. (2008) Third Mission ranking for world class universities: Beyond teaching and research // Higher Education in Europe. Vol. 33 (2-3). P. 195-199.

Аата поступления: 19.06.2019 г.

“THIRD MISSION” IN THE DEVELOPMENT PROGRAMS OF RUSSIAN UNIVERSITIES

(EXEMPLIFIED BY UNIVERSITIES OF THE NORTH-WESTERN FEDERAL DISTRICT)

E. V. KUDRYASHOVA, S. E. SOROKIN

NORTHERN (ARCTIC) FEDERAL UNIVERSITY NAMED AFTER M.V. LOMONOSOV

The paper analyses the development programmes of a number of universities of the NorthWestern federal district of Russia as pertains to the implementation of the "third mission" - execution of social functions. The authors specify the features of the implementation of the "third mission", depending on the status of the university, its mission, goals and objectives, the main directions of interaction of higher education institutions with regional authorities, the sphere of production and the local community.

Most universities see commercialization of scientific knowledge and technology transfer as a significant element, focusing on the innovative and entrepreneurial component of the implementation of the "third mission". The priority is also to establish mutually beneficial partnerships with production, government agencies and authorities, technology transfer, consulting and expertise. Participation in the social and cultural life of a region or macroregion is usually considered second.

The authors conclude that the success of the "third mission" will largely depend on the position of the Federal higher education authorities that should clearly indicate the importance of this direction.

Keywords: university, national university, federal university, national research university, reference university, "third mission", higher education in Russia; North-Western federal district

\section{REFERENCES}

Auzan, A. A. (2013) Missiia universiteta: vzgliad ekonomista. Voprosy obrazovaniia, no. 3, pp. 266-286. (In Russ.).

Golovko, N. V., Zinevich, O. V., Ruzankina E. A. (2018) Tret'ia missiia universiteta i model' mnogopol'zovatel'skogo upravleniia dlia regional'nogo razvitiia. Sravnitel' naia politika, no. 1, pp. 5-17. (In Russ.).

Dobren'kov, V. I. and Nechaev, V. Ia. (2003) Obshchestvo i obrazovanie. Moscow, INFRA-M. 381 p. (In Russ.).

Zinevich, O. V. and Ruzankina E. A. (2014) Universitet kak nauchnyi i sotsial'nyi institut v sovremennom rossiiskom obshchestve. Vysshee obrazovanie v Rossii, no. 7, pp. 37-43. (In Russ.).

Itskovits, G. (2010) Troinaia spiral'. Universitety - predpriiatiia - gosudarstvo. Innovatsii $v$ deistvii : transl. from Engl., ed. by A. F. Uvarov. Tomsk, Izd-vo Tomsk, gos. un-ta sistem upr. i radioelektroniki. 238 p. (In Russ.).

Klark, B. R. (2011) Sozdanie predprinimatel'skikb universitetov: organizatsionnye napravleniia transformatsii / transl. by A. Smirnov. Moscow, Izd. dom Gos. un-ta - Vysshei shkoly ekonomiki. 240 p. (In Russ.).

Markhl M., Pausist A. (2013) Metodologiia otsenki tret'ei missii universitetov. Nepreryvnoe obrazovanie: XXI vek, vol. 1, pp. 1-13. (In Russ.).

Medushevskii, N. A. (2016) Interpretatsiia tret'ei roli universitetov na sovremennom etape. Vestnik RGGU. Seriia «Politologiia. Istoriia. Mezbdunarodnye otnosheniia. Zarubezbnoe regionovedenie. Vostokovedenie», no. 3, pp. 19-31. (In Russ.).

Nagornov, V. A. and Perfil'eva, O. V. (2010) Otsenka roli vuzov v regional'nom razvitii: formirovanie ustoichivykh partnerstv dlia vzaimodeistviia. Vestnik mezhdunarodnykb organizatsii: obrazovanie, nauka, novaia ekonomika, no. 4, pp. 60-86. (In Russ.). 
Perfil'eva, O. V. (2011) Universitet i region: na puti k realizatsii tret'ei funktsii. Vestnik mezhdunarodnykb organizatsii, no. 1 (32), pp. 133-144. (In Russ.).

Smirnov V. A., Fadeeva L. A., Punina K. A. and Golubev S. V. (2013) Universitet i regional'nye (gorodskie) soobshchestva: modeli sosushchestvovaniia i upravlencheskie mekhanizmy integratsii (rossiiskii i evropeiskii opyt). Ars Administrandi, no. 4, pp. 102-117. (In Russ.).

Dan, M. C. (2012) The Third Mission of Universities in the Development Strategy of Vienna City. Informatica. Economica, vol. 16, no. 4, pp. 49-56.

Jongbloed, B. (2008) Seven Indicators for Mapping University regional Interactions. ENID PRIME Indicators Conference in Oslo, 26-28 May 2008. London, Publisher Centre for Higher Education. $123 \mathrm{p}$.

Montesinos, P., Carot, J.-M. and Mora, F. (2008) Third Mission ranking for world class universities: Beyond teaching and research. Higher Education in Europe, vol. 33 (2-3), pp. 195-199.

Submission date: 19.09.2019.

Кудряшова Елена Владимировна - доктор философских наук, профессор, ректор Северного (Арктического) федерального университета имени М. В. Аомоносова, действительный член Российской академии естественных наук. Адрес: 163002, Россия, г. Архангельск, наб. Северной Авины, д. 17. Тел.: +7 (8182) 21-89-20. Эл. адрес: e.kudryashova@narfu.ru

Сорокин Сергей Эдуардович - кандидат политических наук, доцент, проректор по социальным вопросам и воспитательной работе Северного (Арктического) федерального университета имени М. В. Аомоносова. Адрес: 163002, Россия, г. Архангельск, наб. Северной Авины, А. 17. Тел.: +7 (8182) 21-89-87. Эл. адрес: s.sorokin@narfu.ru

Kudryashova Elena Vladimirovna, Doctor of Philosophy, Professor, Rector, Northern (Arctic) Federal University named after M. V. Lomonosov; Full Member, Russian Academy of Natural Sciences. Postal address: 17, Severnoy Dviny Emb., Arkhangelsk, Russian Federation, 163002. Tel.: +7 (8182) 21-89-20. E-mail: e.kudryashova@narfu.ru

Sorokin Sergey Eduardovich, Candidate of Political Science, Associate Professor, Vice-Rector for Social and Educational Issues, Northern (Arctic) Federal University named after M. V. Lomonosov. Postal address: 17, Severnoy Dviny Emb. Arkhangelsk, Russian Federation, 163002. Tel.: +7 (8182) 21-89-87. E-mail: s.sorokin@narfu.ru 